\title{
Photocatalytic Degradation of Methyl Violet Dye Using Calcium Carbonate Nanoparticles Synthesized by Precipitation Method
}

\author{
K Jeyasubramanian ${ }^{1 *}$, M Muthuselvi ${ }^{1 * *}$, M Muthuselvan ${ }^{2 * * *}$ \\ *Senior Professor, ${ }^{* *}$ Research Scholar, ${ }^{* * *}$ Student, 'Department of Chemistry, Mepco Schlenk Engineering College, Sivakasi, \\ Tamil Nadu, India. '2Department of Electronic and Communication, Sri Krishna College of Technology, Kovaipudur, Coimbatore, India.
}

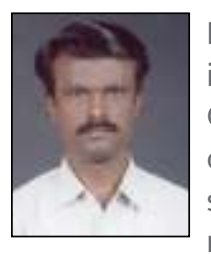

Dr. K. Jeyasubramanian is currently working as a Senior Professor in the Department of Chemistry at Mepco Schlenk Engineering College, Sivakasi. He obtained his B.Sc. and M.Sc. degree in Chemistry from Madurai Kamaraj University, Madurai. He obtained his Ph.D. in Bio-Inorganic chemistry from the same University. He has obtained funding from various funding agencies such as ISRO-Respond, DRDO, DST, and MSME. He has published many international peer reviewed journals with citations more than 2500.

Corresponding author - Dr. K. Jeyasubramanian (kjeya@mepcoeng.ac.in)

Chettinad Health City Medical Journal 2020; 9(1): 5 - 10

DOI: https://doi.org/10.36503/chcmj9(1)-02

\begin{abstract}
Background: The problem associated with the textile industries are the direct discharge of coloring chemicals into water body that causes threat to the aquatic lives.

Objectives: Photocatalytic degradation of methyl violet dye has been studied by employing inexpensive calcium carbonate nanoparticles $\left(\mathrm{CaCO}_{3} \mathrm{Nps}\right)$ prepared by a simple precipitation method.

Materials and Methods: As prepared $\mathrm{CaCO}_{3} \mathrm{Nps}$ are characterized using XRD, FESEM, UV-visible analysis, etc. Results: The XRD pattern exhibits a well resolved peaks characteristic to rhombohedral crystal phase with crystallite size of $82 \mathrm{~nm}$. FESEM image reveals about the morphology of $\mathrm{CaCO}_{3} \mathrm{Nps}$ which is in irregular shape with size ranges from 100 to $200 \mathrm{~nm}$. Photocatalytic activity of $\mathrm{CaCO}_{3} \mathrm{Nps}$ has been checked by degrading aqueous methyl violet dye solution as model organic pollutant exposing to sunlight.

Conclusions: Degradation of methyl violet dye has been followed spectro photometrically at a wavelength of $\lambda_{\max }=579 \mathrm{~nm}$. Complete degradation of organic dye is noticed at a shorter duration of $40 \mathrm{~min}$.

Key words : Calcium carbonate nanoparticles; Precipitation technique; Photocatalytic degradation; UV-Vis analysis.
\end{abstract}

\section{Introduction}

The present decade is considered as the nanotechnology era, since nano material-based devices had been extensively used in nano-electronics, textile industries, agriculture, catalysis, coating, etc. ${ }^{1-5}$ One of the problem associated with the textile industries are the direct discharge of coloring chemicals like dyes and pigments into natural water resources. It is a major threat and endangers the aquatic lives. The color present in the effluent blocks the sunlight and cause disturbance to the natural growth cycles of many aquatic organisms.6, 7 The heavy metals, organic and inorganic complexes used in making of pigments and dyes are highly toxic and their deposition influences severe health risk.8, 9 Obviously, the dye effluents from the textile and other industries have been considered as major pollutants that disturb the ecosystem and affects quality of the environment.10, 11 Majority of the effluents is discharged during the production and application process in the dye industries and therefore has to receive attention. Among the various kinds of dyes, azo dyes are popular dyes that are most commonly used in the textile industries. ${ }^{12,13}$ However, regarding its disposal after usage, industries have adopted various physical techniques such as coagulation by chemical agents, usage of ion exchange, activated carbon, ultrafiltration, reverse osmosis, etc. ${ }^{14}, 15$ Although, these techniques convert the organic compounds present in the water into a secondary pollutant like sludge, needs further treatment. Furthermore, such additional techniques required to treat the secondary pollutants enhances the cost of remediation. ${ }^{16,17}$

Photocatalysis is a method used to degrade organic compounds found in waste water by mineralizing them into simplest compounds like $\mathrm{H}_{2} \mathrm{O}, \mathrm{CO}_{2}$, etc. Nano photocatalysts have been studied extensively since they have favorable combination of electronic structure, light absorption properties; charge 
transport characteristics, etc. ${ }^{18,} 19$ Among the different kinds of photocatalysts, the prominent nanocatalysts extensively used are $\mathrm{TiO}_{2}, \mathrm{ZnO}, \mathrm{SnO}_{2}$, etc. $^{20-23}$ However, reports about the usage of $\mathrm{CaCO}_{3}$ Nps as photocatalyst against the degra- dation of organic pollutant are scarce. Pei et al. ${ }^{23}$ prepared calcium carbonate micro rods using hydrothermal method and used as an effective photo-catalyst to degrade methyl violet dye with degradation efficiency of $72.29 \%$ at an exposure time of $4 \mathrm{~h}$. Besides, other types of carbonate- based particles of micron size are also used as photocatalyst in the degradation studies of organic pollutants. ${ }^{25-27}$ Though all these literatures dealt with the photo-catalytic activity of micron-sized carbonate, the micron sized carbonate particles exhibit photo-catalytic behavior and its influence of nano size effect is not yet reported. If the photo-catalytic carbonates are in nano size, the overall surface area of the photo-catalyst increases resulting in the inclination of surface-active sites. Therefore, the specific site for photo-catalytic degradation process increases drastically that might enhance the rate of degradation of the pollutant.

In this context, $\mathrm{CaCO}_{3} \mathrm{Nps}$ prepared by a simple precipitation technique is used as a photo-catalyst to degrade methyl violet dye in aqueous condition. Like traditional photo-catalyst $\left(\mathrm{TiO}_{2}, \mathrm{ZnO}, \mathrm{SnO}_{2}\right.$, etc.), $\mathrm{CaCO}_{3} \mathrm{Nps}$ also displays excellent photocatalytic activity towards the degradation of organic pollutant within a short span of time.

\section{Experimental procedure}

\section{Preparation of $\mathrm{CaCO}^{3} \mathrm{Nps}$}

Calcium chloride $(1.47 \mathrm{~g}, 0.01 \mathrm{M})$ is dissolved in $50 \mathrm{ml}$ of distilled water. To this solution $1.06 \mathrm{~g}(0.01 \mathrm{M})$ of sodium carbonate dissolved in $50 \mathrm{ml}$ of water is gradually added with continuous stirring. Instantly, a white precipitate of $\mathrm{CaCO}_{3}$ is formed. Addition of sodium carbonate solution is continued for a period of 30 mins with constant stirring. Formed white precipitate is separated by filtration and washed thoroughly with distilled water to remove unreacted salts. White $\mathrm{CaCO}_{3} \mathrm{Nps}$ particles are dried in hot air oven at $105^{\circ} \mathrm{C}$ for $1 \mathrm{hr}$. The dried powder is collected and stored in vacuum.

\section{Photocatalytic degradation of methyl violet}

$1 \mathrm{mg}$ of crystal violet is weighed accurately and dissolved in $100 \mathrm{ml}$ of distilled water. $0.1 \mathrm{~g}$ of as obtained $\mathrm{CaCO}_{3} \mathrm{Nps}$ is mixed with $100 \mathrm{ml}$ of distilled water and then sonicated for 10 mins using probe type sonicator (SONICS, US). Nanoparticles dispersed solution appeared like a turbid solution, since $\mathrm{CaCO}_{3} \mathrm{Nps}$ are uniformly distributed. To this solution, aqueous methyl violet solution is added, stirred thoroughly and mixture is exposed to sunlight. Once in 10 mins, an aliquot of the exposed mixture is collected and its optical absorption is recorded using UV-Vis absorption spectrometer (Perkin Elmer, Lambda 25, USA) at $\lambda_{\max }=579 \mathrm{~nm}$, whereby it is possible to evaluate the reduction in concentration of methyl violet dye.

\section{Results and discussion}

The XRD pattern obtained for $\mathrm{CaCO}_{3} \mathrm{Nps}$ is shown in Fig. 1. All reflection peaks in Fig. 1 can be readily indexed to pure rhombohedral phase of $\mathrm{CaCO}_{3} \mathrm{Nps}$. The diffraction peaks found at $2 \theta=23.08^{\circ}, 29.35^{\circ}$, $35.93^{\circ}, 39.36^{\circ}, 43.10^{\circ}, 47.12^{\circ}, 47.45^{\circ}, 48.44^{\circ}, 56.52^{\circ}$, $57.39^{\circ}, 60.69^{\circ}, 63.03^{\circ}, 64.65^{\circ}, 65.59^{\circ}, 70.21^{\circ}, 72.9^{\circ}$, and $77.17^{\circ}$ are labeled to (012), (104), (110), (113), (202), (024), (018), (116), (211), (122), (214), (125), (300), (0012), (0210), (128), and (1112) planes respectively is well resembled with the JCPDS No. $85-1108 .^{28}$

The crystallite size (D) of $\mathrm{CaCO}_{3} \mathrm{Nps}$ has been calculated using the Scherrer equation,

$$
D=k \lambda / \beta \cos \theta
$$

where $\beta=$ FWHM (full-width at half-maximum or half-width) is in radian, $\theta$ is the position of the diffraction peak, $k$ is the so-called shape factor, which usually takes a value of about 0.9 , and $\lambda$ is the wavelength of X-ray used (1.5406 $\AA$ for Cu Ka). The average crystallite size of $\mathrm{CaCO}_{3} \mathrm{Nps}$ has been calculated as $82 \mathrm{~nm}$.

\section{FESEM analysis}

FESEM image of $\mathrm{CaCO}_{3} \mathrm{Nps}$ recorded using Carl Zeiss SUPRA-55 is depicted in Fig. 2a-b. The micrographs are taken in different magnifications like $60,000 \times$ and $1,20,000 \times$ respectively at a working distance of $10.8 \mathrm{~mm}$. The operating voltage used for retrieving the image is $24 \mathrm{kV}$. The $\mathrm{CaCO}_{3} \mathrm{Nps}$ shows irregular shaped structures with size ranges from $100 \mathrm{~nm}$ to $200 \mathrm{~nm}$. The nanoparticles are found agglomerated and fused together with each other.

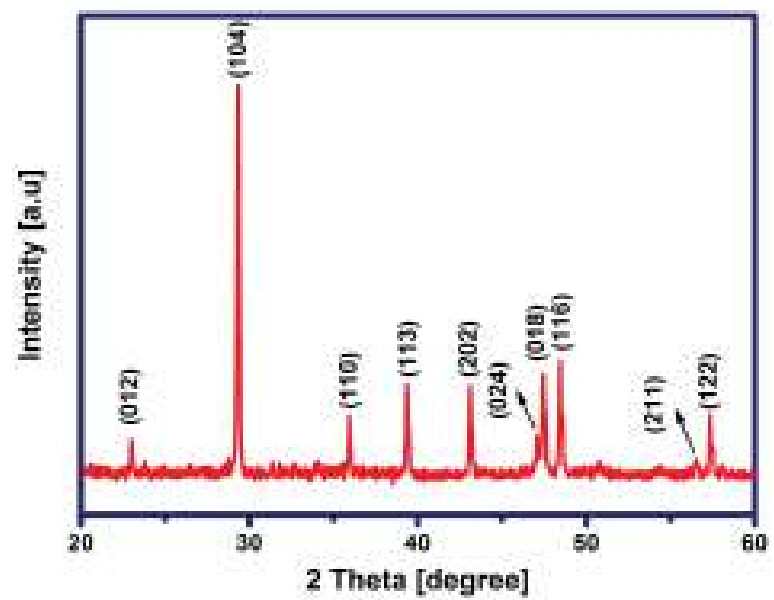

Figure 1: XRD pattern of calcium carbonate nanoparticles 

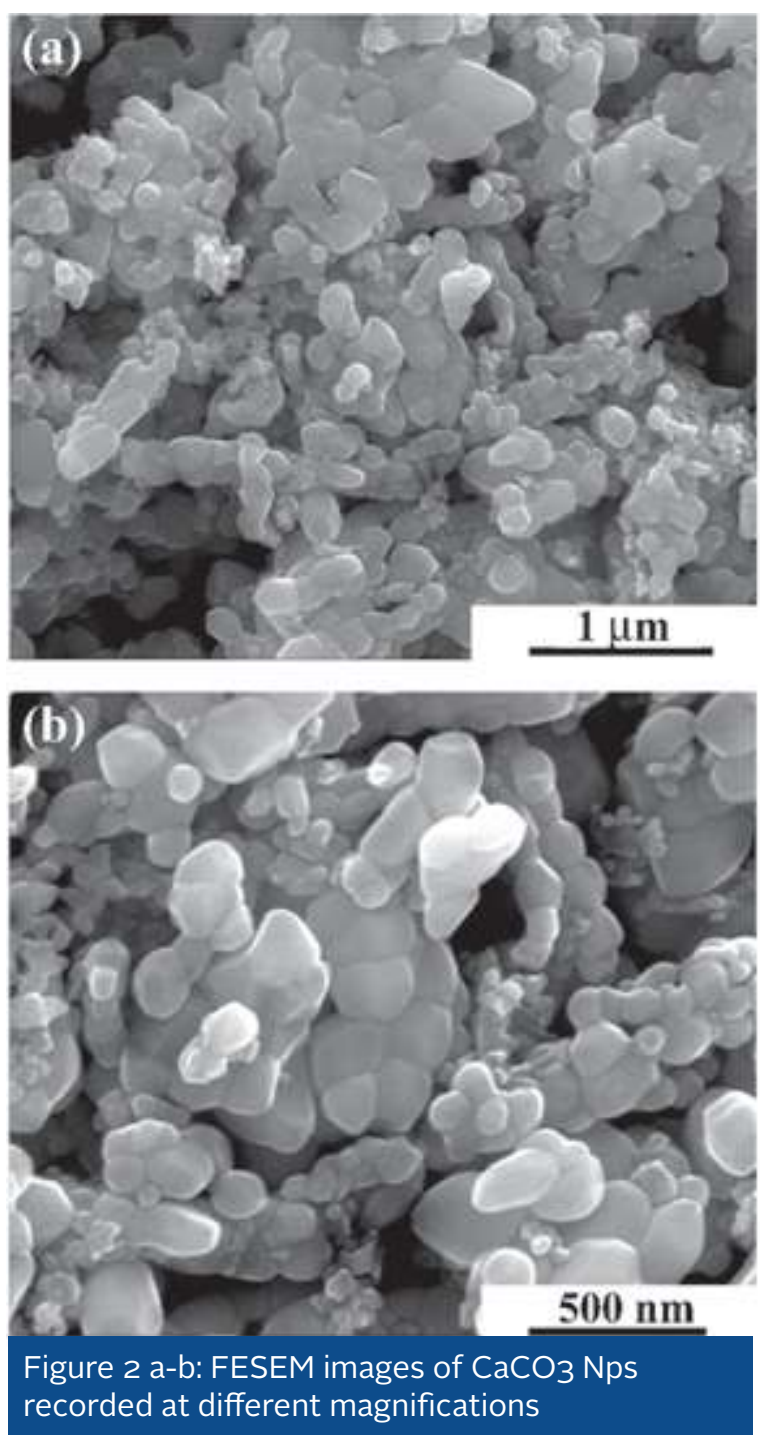

\section{UV-Vis analysis}

UV-Vis reflectance spectrum of $\mathrm{CaCO}_{3} \mathrm{Nps}$ recorded in the range of $300 \mathrm{~nm}$ to $800 \mathrm{~nm}$ using UV-Vis spectrophotometer, Shimadzu, UV-2450, Japan is shown in Fig. 3. From the plot, it is found that the $\mathrm{CaCO}_{3} \mathrm{Nps}$ has an absorption band edge near UV region and therefore there is a possibility of excitation to occur at the characteristic wavelength.

The energy band gap exist between the conduction band and valence band of $\mathrm{CaCO}_{3} \mathrm{Nps}$ can be determined from the data obtained from reflectance spectra using Kubelka-Munk function $F(R \infty)$, which is expressed as,

$$
F(R)=(1-R)^{2} / 2 R
$$

Where, $R$ is the reflectance value and $F(R)$ is equivalent to the absorption coefficient. For determining the band gap of the prepared nano particles, a graph is plotted with $\left[F(R)^{*} h u\right]^{2}$ along $Y$-axis and hu(eV) along $\mathrm{X}$-axis [inset image given in Fig. 3]. Intercept made at $\mathrm{X}$-axis by drawing a tangent from the linear

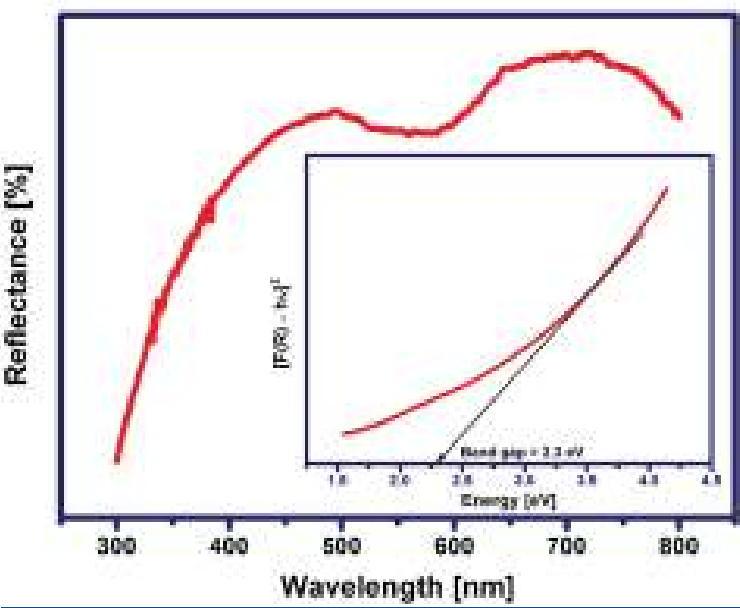

Figure 3: Reflectance spectra and [inset] band gap determination of $\mathrm{CaCO}_{3} \mathrm{Nps}$

part of the graph gives the band gap energy of the $\mathrm{CaCO}_{3} \mathrm{Nps}$ is equal to $2.3 \mathrm{eV}$.

\section{Photodegradation of methyl violet dye}

Experimentally, the photodegradation of methyl violet dye catalyzed by $\mathrm{CaCO}_{3} \mathrm{Nps}$ has been followed through UV-Vis spectrometer. The mixture containing $\mathrm{CaCO}_{3} \mathrm{Nps}$ and methyl violet dye prepared by taking $1 \mathrm{mg}$ of dye dissolved in $100 \mathrm{ml}$ of distilled water and $100 \mathrm{ml}$ of $\mathrm{CaCO}_{3} \mathrm{Nps}$ (0.1 g dispersed in $100 \mathrm{ml}$ water) dispersion exposed to sunlight (around $12.00 \mathrm{pm}$ ). Till the disappearance of violet color, the contents are kept at sunlight. Periodically, the change in color of the dye is recorded spectroscopically. Violet color $(\lambda=579 \mathrm{~nm})$ of the chosen azo dye is characterized to azo bonds linked with chromophores and auxo- chromes. Azo bonds are active bonds that can degrade into colorless fragments by reactive species generated in the solution in an in-situ manner while exposing to sunlight. Hydroxyl radical, e-/h+ pair, $\mathrm{O}_{2}$ - species, etc. are responsible for the cleavage of azo bonds that leads to the degradation of organic network. ${ }^{29}$ The degrada- tion of MV by exposing to sunlight in the presence of $\mathrm{CaCO}_{3} \mathrm{Nps}$ is described below,

$$
\begin{array}{lll}
\mathrm{CaCO}_{3}+\mathrm{hv} & \rightarrow & \mathrm{CaCO}_{3}\left(\mathrm{e}^{-} / \mathrm{h}^{+}\right. \text {pair } \\
& \text { formation }) \\
\mathrm{e}^{-}+\mathrm{O}_{2} & \rightarrow \mathrm{O}_{2} \cdot- \\
\mathrm{H}_{2} \mathrm{O}+\mathrm{O}_{2} \cdot- & \rightarrow \mathrm{OOH}^{\cdot}+\mathrm{OH}^{-} \\
2 \mathrm{OOH} \cdot & \rightarrow \mathrm{O}_{2}+\mathrm{H}_{2} \mathrm{O}_{2} \\
\mathrm{OOH} \cdot+\mathrm{H}_{2} \mathrm{O}+\mathrm{e}- & \rightarrow \mathrm{H}_{2} \mathrm{O}_{2}+\mathrm{OH}^{-} \\
\mathrm{H}_{2} \mathrm{O}_{2}+\mathrm{e}_{-} & \rightarrow \mathrm{OH}^{\cdot}+\mathrm{OH}^{-} \\
\mathrm{H}_{2} \mathrm{O}_{2}+\mathrm{O}_{2} \cdot- & \rightarrow \mathrm{OH}^{\cdot}+\mathrm{OH}^{-}+\mathrm{O}_{2} \\
\mathrm{e}^{-} / \mathrm{h}^{+} \text {pair/OH} \cdot / & & \\
\mathrm{O}_{2} \cdot-/ \mathrm{CaCO}_{3} \cdot+\text { dye } & \rightarrow & \text { Dye degradation }
\end{array}
$$

In sunlight, $\mathrm{CaCO}_{3} \mathrm{Nps}$ get excited; transfer an electron to the conduction band [Eq. (3)]. The excitation of e- causes effective charge separation 


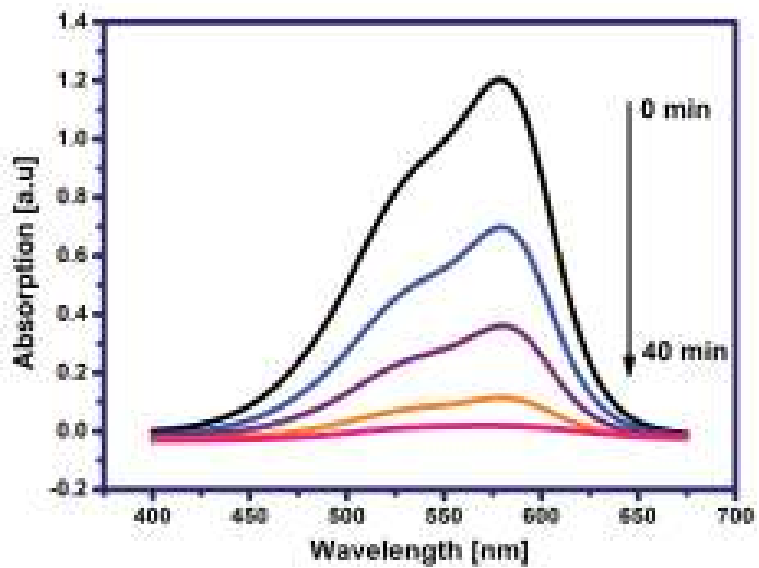

Figure 4a: Photo-catalytic degradation of MV using $\mathrm{CaCO}_{3} \mathrm{Nps}$

and leads to the production of $\mathrm{e}^{-} / \mathrm{h}^{+}$pair, which is a key step for the photo-catalytic degradation process. ${ }^{29} \mathrm{e}^{-}$found on the conduction band of $\mathrm{CaCO}_{3} \mathrm{Nps}$ reacts with the dissolved oxygen present in water and produces super oxide radical [Eq. (4)]. These radicals further react with oxygen and organic molecules produces hydrogen peroxide [Eq. (5-7)]. Hydrogen peroxide further generates hydroxyl radicals which are powerful oxidizing agents [Eq. (8, 9)], capable of attacking dye molecules and degrade them [Eq. (10)].

The spectroscopic investigation of photo-catalytic degradation of MV at an interval of 10 mins is recorded using UV-Vis spectrometer is depicted in Fig. 4 a. From the spectra, it is visualized that the intensity at $\lambda_{\max }=579 \mathrm{~nm}$ found decreases with increase in exposure time. This indicates that the concentration of the dye gets reduced with respect to exposure time. The absorption peak at $\lambda_{\max }=579 \mathrm{~nm}$ almost reaches to zero when the irradiation time is about 40 mins. The remarkable performance of $\mathrm{CaCO}_{3}$ $\mathrm{Nps}$ is due to the efficient charge separation process and the reduction in recombination process as described.

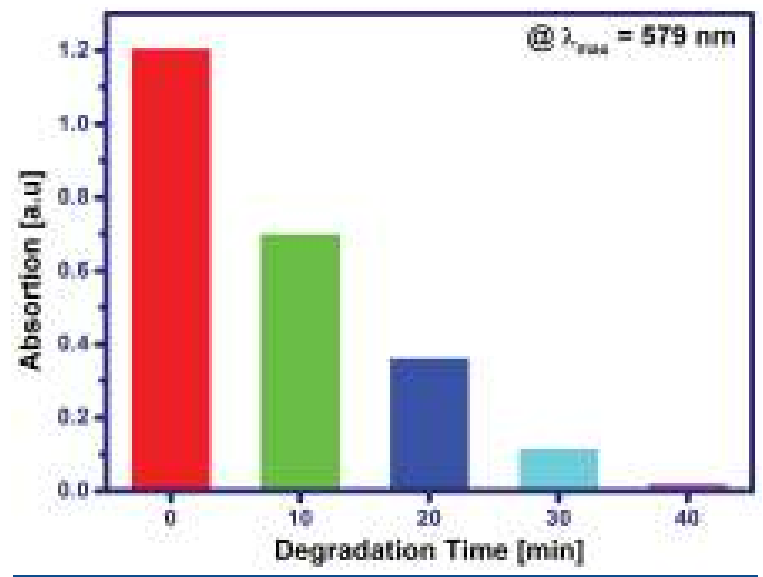

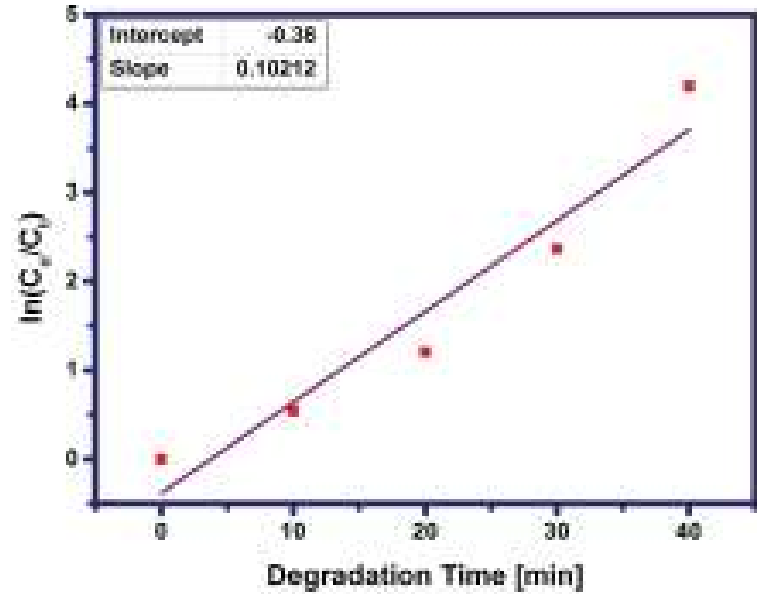

Figure $4 \mathrm{C}$ : In (CO/Ct) vs irradiation time for determining rate constant

Fig. $4 \mathrm{~b}$ indicates about the reduction in optical density at $\lambda_{\max }=579 \mathrm{~nm}$ while exposing to sunlight. From the graph, it is inferred that the optical density gets changed with increase in exposure time and almost equal to zero at about 40 mins of exposure time. From these data, the degradation efficiency of $\mathrm{CaCO}_{3} \mathrm{Nps}$ against methyl violet is evaluated and found as $98.5 \%$. However, there is no reduction in dye concentration when $\mathrm{MV}$ solution is exposed to sunlight without the presence of $\mathrm{CaCO}_{3} \mathrm{Nps}$. These results clearly indicate that the photo-catalytic degradation occurs more efficiently in presence of sunlight along with the catalyst only.

Kinetics of the degradation process is evaluated for low dye concentration that obeys first-order-kinetic reactions. The Langmuir - Hinshelwood relation provides the data for the steady state reaction process is represented as, 30

$$
\begin{aligned}
& \mathrm{dC} / \mathrm{dt}=-\mathrm{K}_{\mathrm{C}} \mathrm{C} \\
& \ln \left(\mathrm{C}_{\mathrm{o}} / \mathrm{C}_{\mathrm{t}}\right)=\mathrm{K}_{\mathrm{c}} \mathrm{t}
\end{aligned}
$$

Where, $\mathrm{Kc}$ is the rate constant, $\mathrm{Co}$ and $\mathrm{Ct}$ is the initial concentration and final concentration of dye after exposing to sunlight at time t respectively. Rate constant of the reaction is calculated by plotting In $\left(C_{0} / C_{t}\right)$ vs. the degradation time [Fig. 4c]. Slope obtained from the graph gives the rate constant Kc, is found to be 0.10212 . Such a high rate constant confirms the degradation of organic dye at faster rate.

\section{Conclusion}

Present study revealed about the preparation of $\mathrm{CaCO}_{3} \mathrm{Nps}$ by simple precipitation method. As obtained $\mathrm{CaCO}_{3} \mathrm{Nps}$ are characterized using XRD, FTIR, FESEM, UV-Vis analysis, etc. Photocatalytic activity of $\mathrm{CaCO}_{3} \mathrm{Nps}$ is studied by degrading aqueous methyl violet solution exposing to sunlight. The prepared nano particle displayed higher 
photo-catalytic activity with a degradation efficiency of $98.5 \%$ within 40 mins. The rate constant of the degradation process is calculated as 0.10212 using Langmuir - Hinshelwood relation. All these results confirmed that the as obtained $\mathrm{CaCO}_{3} \mathrm{Nps}$ possess excellent photocatalytic degradation efficiency towards organic methyl violet dye.

\section{Acknowledgments}

The authors would like to thank the Management and the Principal of Mepco Schlenk Engineering College, Sivakasi, for their constant encouragement shown regarding this work.

\section{References}

1. Ahuja P, Ujjain SK, Kanojia R. Electrochemical behaviour of manganese \& ruthenium mixed oxide@ reduced graphene oxide nanoribbon composite in symmetric and asymmetric supercapacitor. Applied Surface Science. 2018; 427: 102-11.

2. Maddigpu PR, Sawant B, Wanjari S, Goel MD, Vione D, Dhodapkar RS et al. Carbon nanoparticles for solar disinfection of water. Journal of hazardous materials. 2018; 343: 157-65.

3. Tierling J, Kuhlmann $\mathrm{H}$. Emissions of nitrous oxide ( $\left.\mathrm{N}_{2} \mathrm{O}\right)$ affected by $\mathrm{pH}$-related nitrite accumulation during nitrification of $\mathrm{N}$ fertilizers. Geoderma. 2018; 310: 12-21.

4. Sun B, Yang X, Zhao D, Zhang L. First-principles study of adsorption mechanism of $\mathrm{NH}_{3}$ on different $\mathrm{ZnO}$ surfaces on organics photocatalytic degradation purpose. Computational Materials Science. 2018; 141: 133-40.

5. Akpan UG, Hameed BH. Parameters affecting the photocatalytic degradation of dyes using TiO2-based photocatalysts: a review. Journal of hazardous materials. 2009; 170(2-3): 520-9.

6. Borker P, Salker AV. Photocatalytic degradation of textile azo dye over $\mathrm{Ce}_{1}-\mathrm{xSnxO}_{2}$ series. Materials Science and Engineering: B. 2006; 133(s 1-3): 55-60.

7. Pandey J, Singh R. Heavy metals in sediments of Ganga River: up-and downstream urban influences. Appl Water Sci. 2017; 7: 1669-78.

8. Xu D, Shi W, Song C, Chen M, Yang S, Fan W et al. In-situ synthesis and enhanced photocatalytic activity of visible-light-driven plasmonic $\mathrm{Ag} / \mathrm{AgCl} / \mathrm{NaTaO}_{3}$ nano cubes photocatalysts. Applied Catalysis B: Environmental. 2016; 191: 228-34.

9. Gao X, Huang G, Gao H, Pan C, Wang H, Yan J et al. Facile fabrication of $\mathrm{Bi}_{2} \mathrm{~S}_{3} / \mathrm{SnS}_{2}$ heterojunction photocatalysts with efficient photocatalytic activity under visible light. Journal of Alloys and Compounds. 2016; 674: 98-108.
10. Jeyasubramanian K, Hikku GS, Sharma RK Photo-catalytic degradation of methyl violet dye using zinc oxide nano particles prepared by a novel precipitation method and its anti-bacterial activities. Journal of water process engineering. 2015; 8: 35-44

11. Punzi M, Anbalagan A, Börner RA, Svensson BM, Jonstrup $M$, Mattiasson B. Degradation of a textile azo dye using biological treatment followed by photo-Fenton oxidation: evaluation of toxicity and microbial community structure. Chemical Engineering Journal. 2015; 270: 290-9.

12. Rocha CG, Ferreira AA, Yamanaka H. Label-free impedimetric immunosensor for detection of the textile azo dye Disperse Red 1 in treated water. Sensors and Actuators B: Chemical. 2016; 236: 52-9.

13. Krutzler T, Fallmann $H$, Maletzky $P$, Bauer $R$, Malato S, Blanco J. Solar driven degradation of 4-chlorophenol. Catal today. 1999; 54(2-3): 321-7.

14. Mai C, Majcherczyk A, Schormann W, Hüttermann A. Degradation of acrylic copolymers by Fenton's reagent. Polymer degradation and stability. 2002; 75(1): 107-12

15. Mailhot G, Asif A, Bolte M. Degradation of sodium 4-dodecylbenzenesulphonate photoinduced by Fe (III) in aqueous solution. Chemosphere. 2000; 41(3): 363-70.

16. Huang ST, Jiang YR, Chou SY, Dai YM, Chen CC. Synthesis, characterization, photocatalytic activity of visible-light-responsive photocatalysts $\mathrm{BiOxCly/BiOmBrn}$ by controlled hydrothermal method. Journal of Molecular Catalysis A: Chemical. 2014; 391: 105-20.

17. Gao M, Zhu L, Ong WL, Wang J, Ho GW Structural design of $\mathrm{TiO} 2$-based photocatalyst for $\mathrm{H}_{2}$ production and degradation applications. Catal. Sci. Technol. 2015; 5: 4703-26.

18. Yang W, Wen $Y$, Zeng D, Wang $Q$, Chen R, Wang $W$ et al. Interfacial charge transfer and enhanced photocatalytic performance for the heterojunction WO3/BiOCl: first-principles study. J Mater Chem A. 2014; 2: 20770-5.

19. Fu X, Wang J, Huang D, Meng S, Zhang Z, Li L et al. Trace amount of $\mathrm{SnO}_{2}$-decorated $\mathrm{ZnSn}(\mathrm{OH}) 6$ as highly efficient photocatalyst for decomposition of gaseous benzene: synthesis, photocatalytic activity, and the unrevealed synergistic effect between $\mathrm{ZnSn}(\mathrm{OH}) 6$ and $\mathrm{SnO}_{2}$. ACS Catalysis. 2016; 6: 957-68.

20. Zhang ZC, Xu B, Wang X. Engineering nanointerfaces for nanocatalysis. Chemical Society Reviews. 2014; 43: 7870-86.

21. Liu R, Yang WD, Chung ZJ, Chueng HJ. Synthesis and application of $\mathrm{TiO}_{2}$ nanotubes in environmental pollutant removal. International journal of materials research. 2014; 105(4): 397-403. 
22. Omidi A, Habibi-Yangjeh A. Enhancing photocatalytic activity of $\mathrm{ZnO}$ nanostructures by doping with $\mathrm{Ce}+4$ ions prepared in water using ultrasonic irradiation. International Journal of Materials Research. 2014; 105(3): 288-95.

23. Pei LZ, Lin N, Xie YK, Cai ZY. Synthesis of Calcium Carbonate Microrods and Photocatalytic Degradation of Methylene Blue. Journal of Advanced Microscopy Research. 2013; 8: 283-8.

24. Xu C, Liu Y, Huang B, Li H, Qin X, Zhang X et al. Preparation, characterization, and photocatalytic properties of silver carbonate. Applied surface science. 2011; 257(20): 8732-6.

25. Song L, Zhang S, Chen B. A novel visible-light-sensitive strontium carbonate photocatalyst with high photocatalytic activity. Catalysis Communications. 2009; 10: 1565-8.

26. Walsh D, Kim YY, Miyamoto A, Meldrum FC. Synthesis of macroporous calcium carbonate/magnetite nanocomposites and their application in photocatalytic water splitting. Small. 2011; 7: 2168-72.
27. Boro J, Thakur AJ, Deka D. Solid oxide derived from waste shells of Turbonillastriatula as a renewable catalyst for biodiesel production. Fuel Process.Technol. 2011; 92(10): 2061-7.

28. Islam A, Teo SH, Rahman MA, Taufiq-Yap YH Seeded growth route to noble calcium carbonate nanocrystal. PloS one. 2015;10(12).e0144805

29. Jeyasubramanian K, Hikku GS, Sivashakthi M. Synthesis, characterization and photo-catalytic studies of mixed metal oxides of nano $\mathrm{ZnO}$ and SnOx. Materials Science in Semiconductor Processing. 2016; 51: 25-32.

30. Hikku GS, Jeyasubramanian K, Jacobjose J, Thiruramanathan P, Veluswamy P, Ikeda H. Alkyd resin based hydrophilic self-cleaning surface with self-refreshing behaviour as single step durable coating. J Colloid Interface Sci. 2018; 531: 628-41. 